\title{
Symmetrical Short-Circuit Parameters Comparison of DFIG-WT
}

\author{
Prelimnary Communication
}

\author{
Muhammad Shahzad Nazir \\ South China University of Technology, \\ School of Electrical Power Engineering, \\ Guangzhou, 510640, P.R. China \\ epmsn_bhutta88@mail.scut.edu.cn
}

\author{
Qinghua Wu \\ South China University of Technology, \\ School of Electrical Power Engineering, \\ Guangzhou, 510640, P.R. China \\ wuqh@scut.edu.cn
}

\section{Mengshi Li}

South China University of Technology, School of Electrical Power Engineering, Guangzhou, 510640, P.R. China mengshili@scut.edu.cn

\begin{abstract}
Renewable energy with new resources is depleting the fossil fuel-based energy resources. Renewable energy sources (such as wind energy) based power generators are important energy conversion machines and have widely industrial and commercial applications due to their superior performance, and the fact that they endure faults well and are environmentally friendly. The study of the transient behavior of such generators under fault condition has drawn much attention. This study presents Doubly-Fed Induction Generator (DFIG) perturbation during a symmetrical (three-phase) short circuit (SSC) at different points. Simulation results reveal that after a fault occurs, there is decay of SC parameters (transient time, maximum current, steady-state and voltage dip) at the point of common coupling (PCC) and the grid-side converter (GSC) of DFIG. Simulation results depict a more sensitive and robust point during a SSC of DFIG. Current findings present the main difference between the PCC and the GSC during SSC faults. These comparisons provide a more precise understanding of fault diagnosis reliability with reduced complexity, stability, and optimization of the system. This study verified by the simulation results helps us understand and improve the performance of sensor sensibility (measurements), develop control schemes, protection strategy and select a more accurate and proficient system among other wind energy conversion systems (WECS).
\end{abstract}

Keywords - doubly-fed induction generator, renewable energy, short circuit, wind power generation

\section{INTRODUCTION}

Global warming, fossil fuel based political issues, economic competitions, and rapid human population increase demand for energy and numerous problems of energy resources can be alleviated by reducing constantly rising atmospheric carbon dioxide concentrations and adopting large natural energy producing resources (renewable) such as wind, solar, hydro and tidal [1]. Scientifically, wind power has proved to be eco-friendly, with the least environmental impact and the most promising source of electrical power generation [2-3].

The famous "wedges game theory" has recommended the solution to stabilize the world; a renewable energy (i.e. wind energy) resource is one of the best solu- tions among four other solutions. Better human life on Earth can be achieved by the green energy revolution.

Green electrical energy (GEE) can be obtained through the proper technical arrangement of a wind turbine and an induction generator, which is initially converted by aerodynamic energy in the form of kinetic energy to clean electrical energy [4]. Electrical energy (EE) production by wind power was enjoyed for the first time in 1887 by Charles Brush at Cleveland, Ohio. The rated power of that product (DC-generator) was $12 \mathrm{~kW}$ and it was designed to charge batteries.

The induction machine (IM) was invented in 1951 [5]. It had two main types, fixed and variable speed ranges. Variable speed type induction generators are mostly 
used by industry. They are preferred due to their advantages referring to control of power factor at minimal cost, size reduction (20-30\%) and four-quadrant operational converters [3].

The DFIG is commonly used in wind farms; this is an important wind energy conversion system (WECS) having variable-speed capability [6]. These generators are also known as wound rotors or slip-ring induction machines [6-7]. According to the usage based available data, the DFIG is available in different power ranges (1.5 MW-6 MW). Over $70 \%$ of the wind energy market is occupied by the DFIG. A substantial body of literature is dedicated to the advantages of the DFIG-based WECS [8-10].

The WECS is integrated with power grids for the sake of maintaining operability with reliability and grid power quality. The well-known power system operator "grid codes" must follow WTs to meet the implementation of technical standards [11-12]. There are two types of grid code requirements, i.e. static and dynamic requirements. The power flow at the point of common coupling (PCC) and steady state behavior relate to the static requirement, while during grid faults/disturbances of the induction generator we need a dynamic grid code requirement [13-14]. These requirements include the operating range of voltage and frequency, grid-support capability, regulation of power factor, and low voltage ride through (LVRT) or fault ride-through (FRT) capability.

The objective of this paper is to study the integrated and theoretical study of the DFIG-WT during the SSC at two different points and manipulate simulation results. Both points are studied under SSC conditions and simulation results are measured. The collective results of transient time, maximum current, steady state and voltage dipped values are summarized in Table 1. These measured results reveal robustness of different system parameters. That will further contribute to system sensor installations and other control and protection schemes. This study carried out by the power system analysis software PSCAD/ EMTDC yields quick and accurate simulation results. MAT$L A B$ is also user-friendly for simulation, but PSCAD/EMTDC software is quicker for wind turbine simulations.

The rest of the paper is organized as follows: The wind energy extraction method is presented in Section 2. The system description is given in Section 3. Simulation studies and discussion are presented in Section 4. Conclusion is drawn in Section 5.

\section{WIND ENERGY EXTRACTION METHOD}

Power extracted from wind energy plays a significant role in electrical power production. Power can be extracted from the wind by horizontal axis wind turbine (HAWT) and vertical axis wind turbine (VAWT) systems. Modern wind turbine parks use a HAWT with two or three blades [15]. Three-blade turbines are more famous and more commonly used due to their symmetrical loading. A three-blade system is $50 \%$ more expensive compared to a two-blade system [16]. It is inter- esting that most of the countries existing in the world have the sites with an average wind speed of greater than $5 \mathrm{~m} / \mathrm{s}$ with the height of $10 \mathrm{~m}$. This implies that each country is capable of producing wind energy [17].

In a conventional HAWT, a large tower rests on a deep, solid foundation, supporting a nacelle with the rotating blades at the top of the tower. The nacelle consists of a gearbox, a generator, power electronics devices and a yaw mechanism [16]. The starting point of the wind turbine (WT) to produce power at wind speed of $9 \mathrm{mph}(4 \mathrm{~m} / \mathrm{s})$, achieving the rated power at about 29 $\mathrm{mph}(12 \mathrm{~m} / \mathrm{s})$. The WT stops power production at a high wind speed range around $56 \mathrm{mph}(25 \mathrm{~m} / \mathrm{s})$ [18]. It is not convenient to set up the turbines taller than 100-120 m [19]. The height of the WT plays an important role in the wind energy extraction process.

WTs extract wind through rotor blades and transfer it to the hub of the rotor. The hub of the rotor is connected to a low-speed shaft by a gear box. The electrical generator is driven by a high-speed shaft, which converts mechanical energy to electrical energy. That extracted energy is transmitted to the power grid. A variation of wind speed also possesses the power extracted, converted and transmitted to the grid [20].

There are different wind turbine modeling systems to calculate the obtained wind power from wind power turbine systems. The amount of power captured from a wind turbine is governed by the MOD-2 [21] WT modeling system. Mechanical power $(P \mathrm{~m})$ captured by the WT is explained as follows:

$$
P_{m}=\frac{1}{2} \rho \tau R^{2} V_{w}^{3} C_{p}(\lambda, \beta),
$$

where $\rho$ is air density $(\mathrm{kg} / \mathrm{m} 3), \mathrm{R}$ is the radius of turbine blades, Vw represents wind speed $(\mathrm{m} / \mathrm{s})$, and $\mathrm{Cp}(\lambda, \beta)$ is the power performance coefficient (the Betz constant), where lambda $(\lambda)$ is the tip-speed ratio of the rotor blade and the tip speed to the wind speed, and beta $(\beta)$ represents the pitch angle (degree) of blades. The maximum power of $59 \%$ is possibly extracted from the wind (Betz theory) [16].

\section{SYSTEM DESCRIPTION}

The immense demand for electric power has contributed to developing and improving the energy conversion technology. Different arrangements and configurations of WECS have been developed and opportunities for employing various types of generators have been created. The generators used for WECS can be categorized into two main types:

- $\quad$ Fixed speed generators (FSGs),

- $\quad$ Adjustable speed generators (ASGs).

The details of these generators are summarized in [15, 22-23]. FSGs are economically not suitable due to their expensive mechanical construction. ASGs based WECS are commonly used at high-rated power $[15,23]$. 
Due to varying wind speed, researchers and industries have started to pay more attention to the use of ASGs. Furthermore, modern electronic system designs also incorporate the use of power electronics to operate together with variable speed generators. It is the main comparative advantage over FSGs. The DFIG plays a vital role as an electrical generator to support dynamic operation conditions among ASGs. The generators under serious consideration in WEPS are the double-fed induction generator (DFIG) and the synchronous generator (SG).

The main parts of the DFIG-WT system are shown in Fig. 1 and the DFIG parameters are listed in Appendix $A$. The wind turbine system is a combination of mechanical and electrical components, the DFIG generator, the rotor-side converter (RSC), the DC link, the grid-side converter (GSC and its filter), the control system, both fault points, the transformer and load. Controlling parts are modified according to the load or required system.

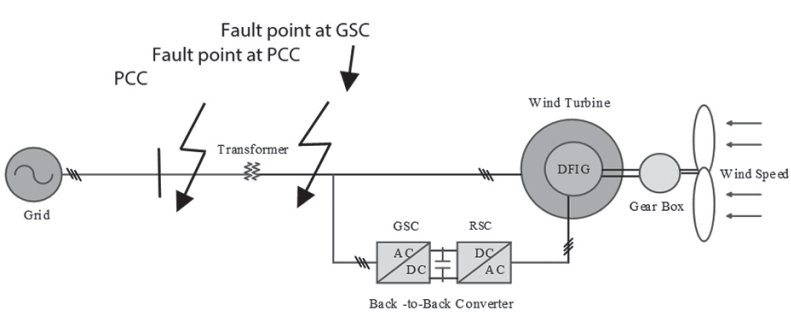

Fig. 1. Schematic diagram of the DFIG-based wind turbine

Generally, advantages of the DFIG-WT system can be summarized as follows [24-25]:

- Economical inverter/converter, because of the converter and filter size compared to other ASGs (a synchronous generator) [24].

- It has the ability to work in a wide range of wind speed.

- A low rating of converters improves system efficiency; a low rating makes the system less lossprone.

- Power factor control can be implemented at lower cost.

- It has four quadrant converters in the rotor circuit that enable control of active and reactive power of the generator.

- By improving the efficiency of energy transferred from wind energy, the DFIG can even generate twice its own rating power at the slip value of $s$ $=-1[26]$.

The DFIG has better performance during a voltage dip, transient time and other perturbation situation than other ASGs systems. All aforementioned properties make the DFIG more reliable and a better choice for WECS. The DFIG has two main operation modes, i.e. sub-synchronous and super-synchronous [27].

\section{A. Super-Synchronous}

When the generator's rotor rotates at a speed greater than its synchronous speed, this operation is called super-synchronous. The slip becomes negative and both the rotor and the stator deliver power to the grid.

\section{B. Sub-Synchronous}

When the generator operates at its synchronous speed, this is called sub-synchronous mode. Obviously, the slip operates in positive mode and a stator winding delivers power to both the grid and a rotor winding. This mode does not exceed the rated power compared to the other super-synchronous mode. This mode has a smaller rotational speed.

\subsection{MATHEMATICAL MODEL OF DFIG}

For mathematical modeling of the DFIG, the stator, the rotor and both fluxes can be represented as [12]:

$$
\begin{gathered}
\vec{v}_{r}=R_{r} \vec{i}_{r}+\frac{d \vec{\psi}_{r}}{d t}-j \omega_{r} \vec{\psi}_{r} \\
\vec{\psi}_{s}=L_{s} \vec{i}_{s}+L_{m} \vec{i}_{r} \\
\vec{v}_{s}=R_{s} \vec{i}_{s}+\frac{d \vec{\psi}_{s}}{d t} \\
\vec{\psi}_{r}=L_{r} \vec{i}_{r}+L_{m} \vec{i}_{s}
\end{gathered}
$$

The rotor winding induced EMF in terms of rotor voltage, so the rotor side current can be expressed as:

$$
\vec{v}_{r}^{r}-\vec{e}_{r}^{r}=R_{r} \vec{i}_{r}^{r}+L_{l r} \frac{d \vec{i}_{r}^{r}}{d t}
$$

The equation above induces the EMF based on stator flux dynamics; it can be induced in the stator reference frame or in the rotor reference frame. The equivalent circuit of the DFIG in Fig. 2 represents its frame references.

$$
\vec{e}_{r}^{r}=c_{s} \cdot \frac{d \vec{\psi}_{s}^{r}}{d t}, \vec{e}_{r}^{s}=c_{s}\left(\frac{d}{d t}-j \omega_{r}\right) \vec{\psi}_{s}^{s}
$$

Here $c_{s}=\frac{L_{m}}{L_{s}}$ is the coupling factor of stator-side converters.

Fig. 2 represents the external supply of the DFIG by $\mathrm{RSC}$; the rotor-side equivalent circuit of the generator is developed by using Equation 6 .

$$
\begin{gathered}
A_{s}=-\frac{3 L_{m}}{2 L_{s}} V_{d s} i_{d r} \\
B_{s}=-\frac{3 L_{m}}{2 L_{s}} V_{d s}\left(i_{q r}+\frac{V_{d s}}{\omega_{s} L_{m}}\right)
\end{gathered}
$$




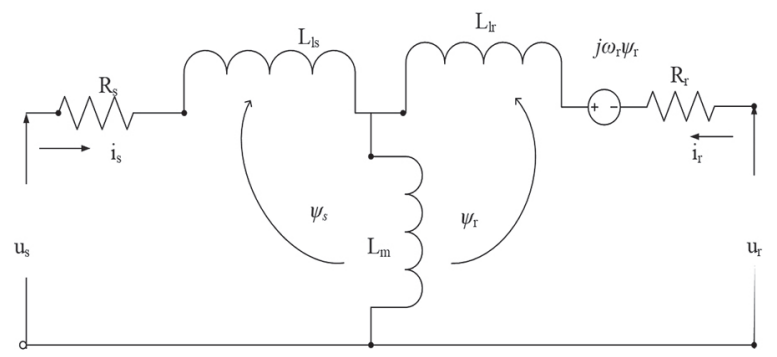

Fig. 2. Stator reference frame equivalent circuit of the DFIG

Stator voltage oriented (SVO) references are expressed at the stator side actively and reactive power is delivered by the DFIG. Fig. 3 represents the rotor equivalent circuit.

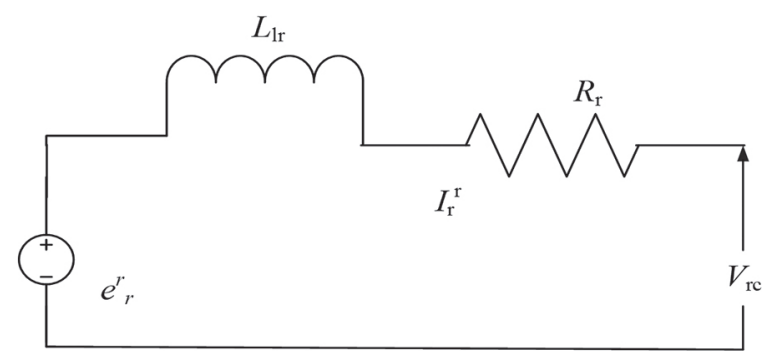

Fig. 3. Rotor reference frame equivalent circuit of the DFIG

Equations 8 and $9(A, B)$ represents the stator active and reactive power. Modeling of the DFIG is described in [28]. The DFIG system has been modeled with the help of the PSCAD/ EMTDC platform.

\section{SIMULATION STUDIES AND DISCUSSION}

It is important for advanced protection, control and compatible schemes to provide smooth operation of the dependent system. It is also necessary the system is understood well before any control or protection scheme is applied. This section of our paper presents simulation results generated by PSCAD/ EMTDC. The simulation system is a single-machine infinite bus system. The parameters of the DFIG-WT and the transformer are standard and they are extracted from the PSCAD library. The values of parameters are developed and set in per-unit with the reference of the rated power and voltage. Considering the perturbation conditions of the DFIG-WT, the proposed short circuit scheme has been applied at different points of the DFIG-based wind energy system. To maintain smooth operation and reliability with grid power quality, an SSC fault was applied at the GSC/machine side and the PCC/highvoltage side of the transformer. What is most important for the implementation of the technical standard is to meet the grid code requirements. There are two types of grid code requirements, i.e. dynamic and static requirements. A static requirement contains steady-state behavior and power flow at the PCC. The steady-state behavior is observed in Figures 4(c) and 5(c). Hence dynamic grid codes look up to the desired responses of the induction generator during grid perturbation. These requirements cover the frequency and voltage, grid supporting capability, power factor regulation, fault ride-through (FRT) or low-voltage ride-through (LVRT) capability operating range simultaneously.

Therefore, the short circuit (SC) fault is applied at different points to observe the transient time, maximum current, steady-state and voltage dip (sag) or fault ridethough (FRT) values. Simulation results were compared and it was concluded that a more sensitive and weak point was under the SSC. The SSC was applied at 1-1.20 $s$ with the resistance range of $0.02 \Omega$. The fault triggering time was kept the same, i.e. two seconds (1-1.20 s) at the PCC and the GSC to collect simulation results. Parameter differences under the SC process is presented in plotted results and in Table 1. Simulation results during the SSC are depicted in Figures 4 and 5 and Table 1. A SSC applied at the PCC or a high voltage side bus transformer of the DFIG-WT. The value of SC resistance is $0.2 \Omega$. Transient time's simulation value during perturbation is depicted in Fig. 4(a). The transient time value given in Table 1 is $1.015 \mathrm{~s}$ (1-1.015 s), while the low voltage side or the GSC value given in Fig. 5(a) is 1.21 $\mathrm{s}(1-1.21 \mathrm{~s})$. The GSC or low voltage side transient time is 0.1 times greater than the one of the PCC or a high voltage side. The maximum current value depicted in Figures 4(b) and 5(b) shows a smaller difference on both sides of the DFIG-WT, i.e. 5.76 p.u and 5.75 p.u. The steady-state of the SSC shows the difference of $0.34 \mathrm{p.u}$ and 0.53 p.u at the PCC and the GSC, which is presented in Figures 4(c) and 5(c), respectively. The PCC or a high voltage side has 0.19 times greater difference than the GSC or a low voltage side. Figures $4(d)$ and 5(d) illustrate the voltage sag value. The SSC of the PCC value is 0.58 p.u-0.21 p.u., while GSC has 0.58 p.u-0.11 p.u. The voltage dipped value difference is 0.50 times, manifesting a more sensitive side of the DFIG-WT. The numerical SSC resulting values numbered in Table 1 and Table 2 depict the DFIG parameters.

In conclusion, this study is available for further SSC studies and other perturbation conditions analysis. Transient time (0.19 times), maximum current, steady-state current value (0.19 times) and the voltage dip (sag) depicted the 0.50 times difference between the PCC and the GSC. These simulation results can be implemented further to build a protection or control strategy for smooth power generation during perturbation, respectively.

Table 1. DFIG-WT SSC simulation results

\begin{tabular}{|ccccc|}
\hline Generator & $\begin{array}{c}\text { Transient } \\
\text { time (sec) }\end{array}$ & $\begin{array}{c}\text { Maximum } \\
\text { current (p.u.) }\end{array}$ & $\begin{array}{c}\text { Steady-state } \\
\text { current } \\
\text { (p.u.) }\end{array}$ & $\begin{array}{c}\text { Voltage } \\
\text { dip/sag } \\
\text { (p.u.) }\end{array}$ \\
\hline DFIG PCC, $\mathrm{h}^{1}$ & 1.015 & 5.76 & 0.34 & $0.58-0.21$ \\
\hline DFIG GSC, $\mathrm{I}^{2}$ & 1.21 & 5.75 & 0.53 & $0.58-0.11$ \\
\hline Difference (\%) & 19 & 0.01 & 19 & 50 \\
\multicolumn{4}{c}{$\mathrm{h}^{1}$ and $\mathrm{I}^{2}$ represent the high and the low voltage side, respectively. }
\end{tabular}




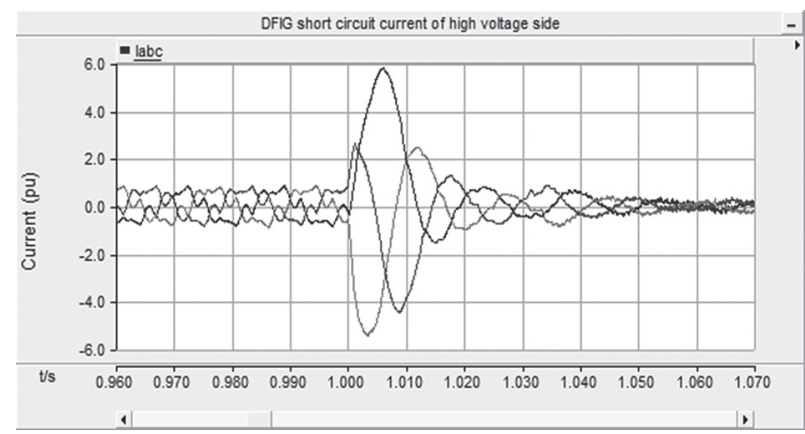

Fig. 4(a). Transient time value under SSC at PCC, $\mathrm{h}^{1}$

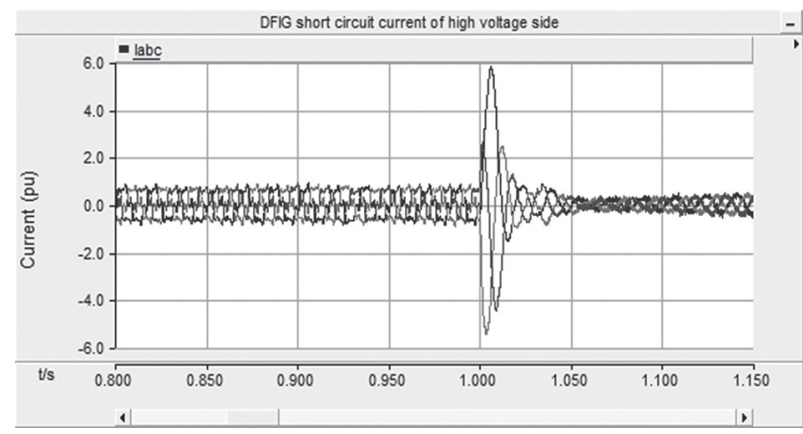

Fig. 4(b). Maximum current value under SSC at PCC, $h^{1}$

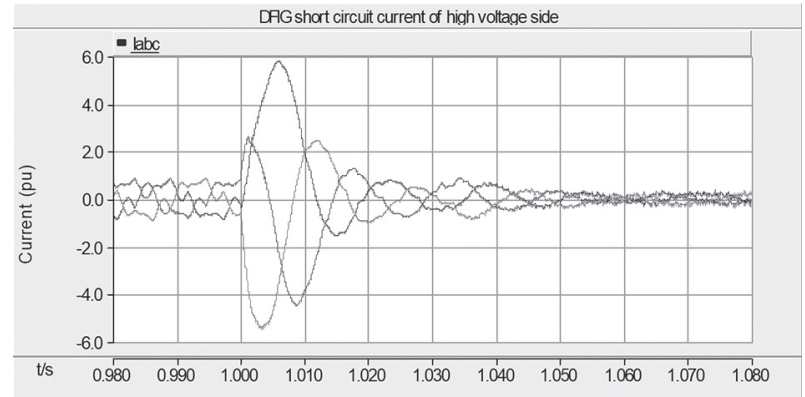

Fig. 4(c). Steady-state value under SSC at PCC, $h^{1}$

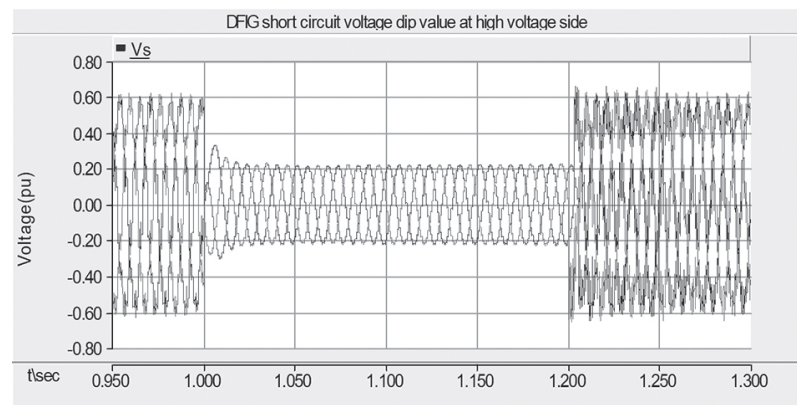

Fig. 4(d). Voltages dip (sag) value under SSC at PCC, $h^{1}$

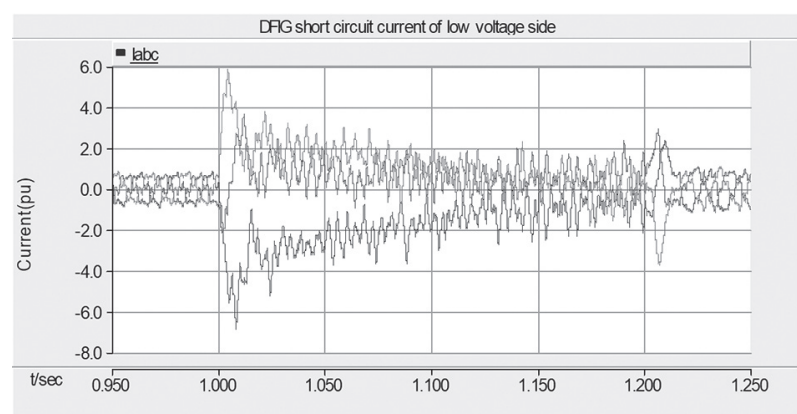

Fig. 5(a). Transient time value under SSC at GSC, I2

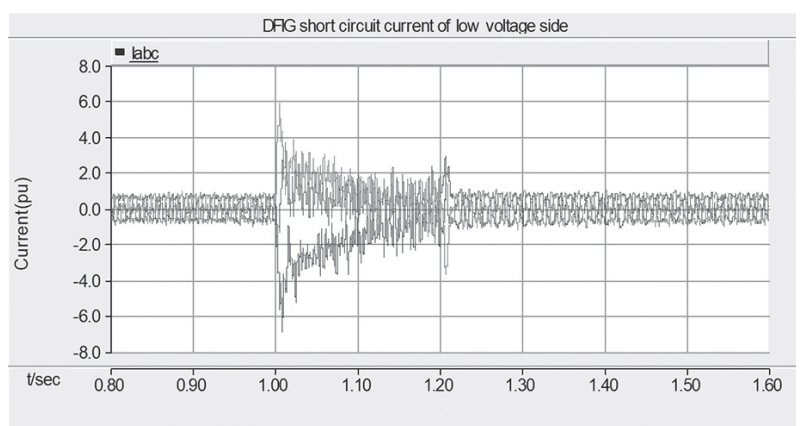

Fig. 5(b). Maximum current value under SSC at GSC, I2

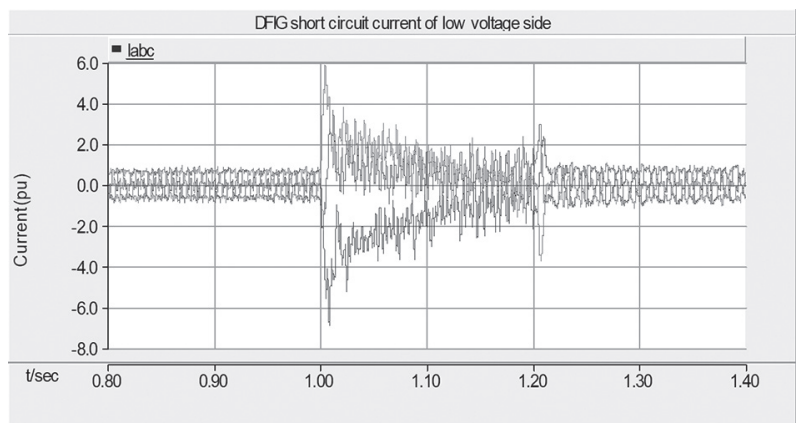

Fig. 5(c). Steady-state value under SSC at GSC, I2

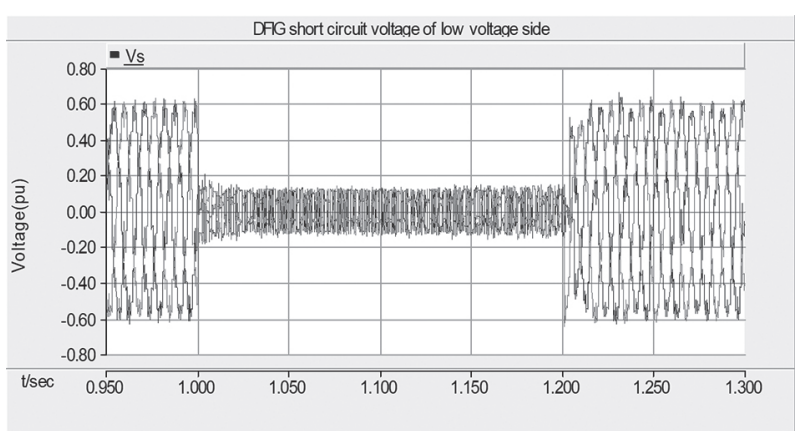

Fig. 5(d). Voltages dip (sag) residual under SSC at GSC, I ${ }^{2}$

\section{CONCLUSION}

This paper investigates the symmetrical short circuit fault of the DFIG-based wind power system. This study is designed to consider the importance of control and protection sensor based schemes of the power system to maintain smooth operation, validation and performance of the DFIG-based system. Increasing the renewable and clean energy demand makes it more important to design protection schemes and control strategies. The DFIG-based wind farms have currently attracted much attention of renewable power generation industry. To suppress the perturbation condition sensor based strategies are installed to maintain the rated range operation of the DFIG. Hence there is still a need to improve these schemes or create advanced compatible schemes to overcome these fault conditions. Before designing these sensor based schemes, there is a need to be well acquainted with FRT, perturbation conditions and the limitations of many WECS parameters. Furthermore, these simulation tests and measurements are applicable to improve stability, sen- 
sibility of sensors, protection schemes and advanced manufacturing quality of high power rating renewable energy systems. This study provided a better understanding of symmetrical fault conditions of various parameters, fault point robustness and sensor rating limits of the system. Its aim is to reduce system failures and security threats and help meet the advance rush demand and optimization of energy by improving cost-effective and environmental concerns.

\section{ACKNOWLEDGEMENT}

Financial support of the Chinese Scholarship Council (CSC) and the South China University of Technology, Guangzhou is acknowledged.

\section{APPENDIX}

Table 2. Double-fed induction generator parameters

\begin{tabular}{cccc} 
Parameters & Value & Parameters & Value (p.u.) \\
\hline Rated power & $2 \mathrm{MW}$ & $\begin{array}{c}\mathrm{L}_{\mathrm{s}} \text { (leakage } \\
\text { inductance) }\end{array}$ & 0.15 \\
\hline Rotor voltage & $1975 \mathrm{~V}$ & $\mathrm{Rs}$ (resistance) & 0.01 \\
\hline Stator voltage & $690 \mathrm{~V}$ & $\mathrm{Rr}$ (resistance) & 0.01 \\
\hline Frequency & $50 \mathrm{~Hz}$ & $\begin{array}{c}\text { Magnetizing } \\
\text { inductance }\end{array}$ & 3 \\
\hline $\begin{array}{c}\mathrm{L}_{\mathrm{m}} \text { (mutual } \\
\text { inductance) }\end{array}$ & $4.5 \mathrm{p.u}$. & $\begin{array}{c}\mathrm{L}_{\mathrm{r}} \text { (leakage } \\
\text { inductance) }\end{array}$ & 0.11 \\
\hline
\end{tabular}

\section{REFERENCES}

[1] M. M. Mansouri, M. Nayeripour, M. Negnevitsky, "Internal electrical protection of wind turbine with doubly fed induction generator", Renewable and Sustainable Energy Reviews, Vol. 55, 2016, pp. 840-855.

[2] A. Eslami, "A three-phase comprehensive methodology to analyze short circuits, open circuits and internal faults of transformers based on the compensation theorem", International Journal of Electrical Power \& Energy Systems, Vol. 96, 2018, pp. 238-252.

[3] M. S. Nazir, Q. H. Wu, M. S. Li, L. L. Zhang, "Symmetrical Short Circuit Parameter Differences of Double Fed Induction Generator and Synchronous Generator based Wind Turbine", Indonesian Journal of Electrical Engineering and Computer Science, Vol. 6, No. 2, 2017, pp. 268-277.

[4] D. Topić, D. Šljivac, M. Gagro, "Influence of Distributed Power Generation from Renewable Energy Sources on Reliability of Distribution Networks",
International Journal of Electrical and Computer Engineering Systems, Vol. 6, No. 2, 2015, pp. 51-56.

[5] J. S. Solís-Chaves, M. Silva Barreto, M. B. C. Salles, V. Martins Lira, R. V. Jacomini, A. J. Sguarezi Filho, "A direct power control for DFIG under a three phase symmetrical voltage sag condition", Control Engineering Practice, Vol. 65, 2017, pp. 48-58.

[6] K. Tamvada, S. Umashankar, P. Sanjeevikumar, "Investigation of Doubly Fed Induction Generator Behavior Under Symmetrical and Asymmetrical Fault Conditions", Advances in Systems, Control and Automation, Lecture Notes in Electrical Engineering, Vol. 442, Springer Singapore, 2018, pp. 347-353.

[7] D. Campos-Gaona, E. L. Moreno-Goytia, O. AnayaLara, "Fault ride-through improvement of DFIG-WT by integrating a two-degrees-of-freedom internal model control", IEEE Transactions on Industrial Electronics, Vol. 60, No. 3, 2013, pp. 1133-1145.

[8] E. J. N. Menezes, A. M. Araújo, N. S. B. da Silva, "A review on wind turbine control and its associated methods", Journal of Cleaner Production, Vol. 174, 2018, pp. 945-953.

[9] M. Rosu, et al., "Multiphysics Simulation by Design for Electrical Machines, Power Electronics, and Drives, One", John Wiley \& Sons, 2018.

[10] S. G. German-Galkin, "An analytic and simulation study of a wound-rotor asynchronous machine at positive slides", Russian Electrical Engineering, Vol. 86, No. 7, 2015, pp. 418-424.

[11] S. Swain, P. K. Ray, "Short circuit fault analysis in a grid connected DFIG based wind energy system with active crowbar protection circuit for ride through capability and power quality improvement", International Journal of Electrical Power \& Energy Systems, Vol. 84, 2017, pp. 64-75.

[12] M. J. Morshed, A. Fekih, "A new fault ride-through control for DFIG-based wind energy systems", Electric Power Systems Research, Vol. 146, 2017, pp. 258-269.

[13] K. V. R. Reddy, N. R. Babu, P. Sanjeevikumar, "A review on grid codes and reactive power management in power grids with WECS", Advances in Smart Grid and Renewable Energy, Lecture Notes in Electrical Engineering, Vol. 435, Springer Singapore, 2018, pp. 525-539. 
[14] G. P. Prajapat, N. Senroy, I. N. Kar, "Wind Turbine Structural Modeling Consideration for Dynamic Studies of DFIG based System", IEEE Transactions on Sustainable Energy, Vol. 8, No. 4, 2017, pp. 1463-1472.

[15] A. Dejanović, M. Babić, M. Tomašević, "Measuring Electric Power Quality of Renewable Energy Sources", International Journal of Electrical and Computer Engineering Systems, Vol. 2, No. 2, 2011, pp. 81-88.

[16] M. Hossain, H. Ali, "Asymmetric fault ride through capability enhancement of DFIG based variable speed wind generator by DC resistive fault current limiter", Proceedings of the Transmission and Distribution Conference and Exposition, Dallas, Texas, USA, 3-5 May 2016, pp. 1-5.

[17] M. E. Hossain, T. E. Wyatt, “Comparison among Series Compensating devices for Transient Stability Enhancement of DFIG Based Variable speed Wind Generator", Proceedings of the Transmission and Distribution Conference and Exposition, Dallas, Texas, USA, 3-5 May 2016, Poster.

[18] F. Blaabjerg, M. Liserre K. Ma, "Power electronics converters for wind turbine systems", IEEE Transactions on Industry Applications, Vol. 48, No. 2, 2012, pp. 708-719.

[19] E. Dupont R. Koppelaar, H. Jeanmart, “Global available wind energy with physical and energy return on investment constraints", Applied Energy, Vol. 209, 2018, pp. 322-338.

[20] A. Gupta, S. N. Singh, D. K. Khatod, "Modeling and simulation of doubly fed induction generator coupled with wind turbine - an overview", Journal of Engineering, Computers \& Applied Sciences, Vol. 2 , No. 8,2013 , pp. $45-54$.
[21] P. M. Anderson, A. Bose, "Stability simulation of wind turbine systems", IEEE Transactions on Power Apparatus and Systems, Vol. 12, 1983, pp. 3791-3795.

[22] J. Lopez, E. Gubia, P. Sanchis, X. Roboam, L. Marroyo, "Wind turbines based on doubly fed induction generator under asymmetrical voltage dips", IEEE Transactions on Energy Conversion, Vol. 23, No. 1, 2008, pp. 321-330.

[23] J. J. Justo, F. Mwasilu J. W. Jung, “Effective protection for doubly fed induction generator-based wind turbines under three-phase fault conditions", Electrical Engineering, 2017, pp. 1-14.

[24] J. Morren, S. W. H. De Haan, "Ridethrough of wind turbines with doubly-fed induction generator during a voltage dip", IEEE Transactions on Energy Conversion, Vol. 20, No. 2, 2005, pp. 435-441.

[25] M. Gholizadeh, A. Oraee, S. Tohidi, H. Oraee, R. A. McMahon, "An analytical study for low voltage ride through of the brushless doubly-fed induction generator during asymmetrical voltage dips", Renewable Energy, Vol. 115, 2018, pp. 64-75.

[26] H. A. Mohammadpour, E. Santi, "Modeling and control of gate-controlled series capacitor interfaced with a DFIG-based wind farm", IEEE Transactions on Industrial Electronics, Vol. 62, No. 2, 2015, pp. 1022-1033.

[27] J. Andreu, J. M. De Diego, I. M. de Alegría, I. Kortabarria, J. L. Martin, S. Ceballos, "New protection circuit for high-speed switching and start-up of a practical matrix converter", IEEE Transactions on Industrial Electronics, Vol. 55, No. 8, 2008, pp. 3100-3114.

[28] M. Zhao, X. Yuan, J. Hu, "Modeling of DFIG Wind Turbine Based on Internal Voltage Motion Equation in Power Systems Phase-Amplitude Dynamics Analysis", IEEE Transactions on Power Systems, 2017 (in press). 